OPEN ACCESS

\section{Atmospheric Plasma Treatment of Carbon Fibers for Enhancement of Their Adhesion Properties}

To cite this article: L L G Silva et al 2014 J. Phys.: Conf. Ser. 511012082

View the article online for updates and enhancements.
Related content
Modification of polyethylene terephthalate by atmospheric pressure dielectric barrier polymer wetting properties
K G Kostov, A L R dos Santos, P A P Nascente et al.
- Surface characteristics analysis of polypropylene treated by dielectric barrier discharge at atmospheric pressure T M C Nishime, A Toth, L R O Hein et al.
- Study of magnetic field enhanced plasma immersion ion implantation in Silicon E J D M Pillaca, K G Kostov and M Ueda

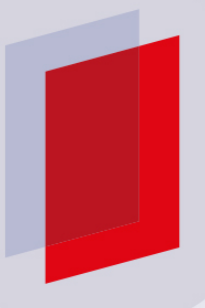

\section{IOP ebooks}

Bringing you innovative digital publishing with leading voices to create your essential collection of books in STEM research. Start exploring the collection - download the first chapter of every title for free. 


\title{
Retraction
}

\section{Atmospheric Plasma Treatment of Carbon Fibers for Enhance- ment of Their Adhesion Properties}

\author{
L L G Silva ${ }^{1,2}$, A L Santos ${ }^{1,2}$, P A P Nascente ${ }^{3}$ and K G Kostov ${ }^{2}$ \\ ${ }^{1}$ Technological Faculty of Pindamonhangaba-FATEC, Rodovia Vereador Abel \\ Fabrício Dias, 4010, Pindamonhangaba, SP, 12445-010, Brazil \\ ${ }^{2}$ Department of Physics and Chemistry, State University of São Paulo - UNESP, \\ Avenida Dr. Ariberto Pereira da Cunha, 333, Guaratinguetá, SP, 12516-410, Brazil \\ ${ }^{3}$ Department of Material Engineering, Federal University of São Carlos - UFSCar, \\ Via Washington Luis, km 235, São Carlos, SP 13565-905, Brazil
}

Published 7 May 2014

The article was originally submitted to the editor of this volume but was withdrawn by the authors who subsequently submitted the work to the journal IEEE Transactions on Plasma Science, where it has since been published, [1]. As the publication in [1] pre-dates the publication in JPCS we are withdrawing this version to remove the duplication. The editor of this volume, L Soto, apologises for any inconvenience caused to the authors and to readers.

[1] IEEE Transactions on Plasma Science 41 (2) , art. no. 6412809 , pp. 319-324. 


\section{Atmospheric Plasma Treatment of Carbon Fibers for Enhancement of Their Adhesion Properties}

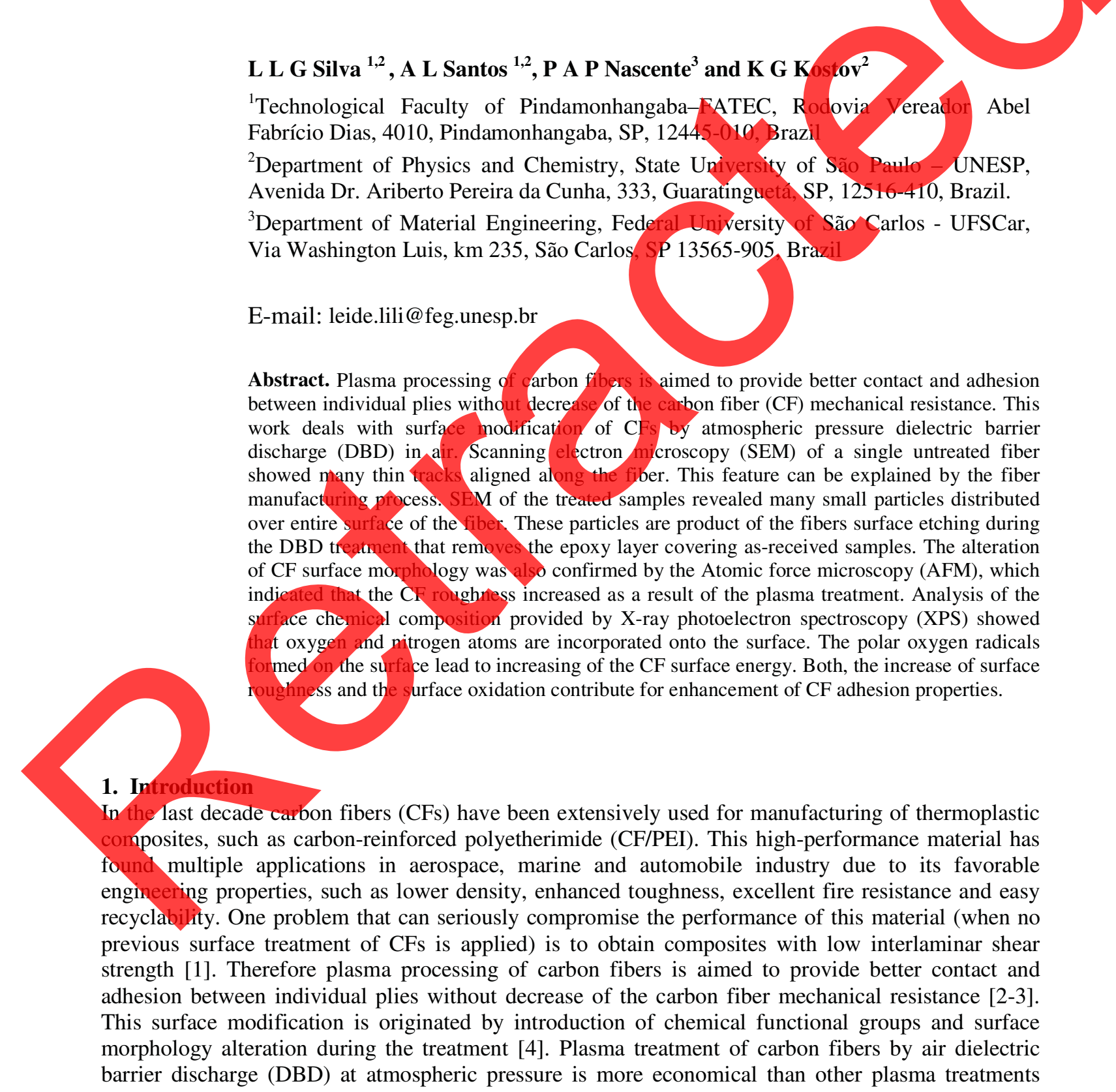


because it needs no closed chambers, special gases and expensive vacuum equipment [3]. Therefore it permits large-scale industrial processing more easily than low pressure plasmas [2].

Currently other materials, such as polyester textile materials [5], Twaron fibers [4], polyester fabric with fluoropolymers [6] and epoxy composites [7], have been treated with atmospheric pressure plasmas in order to improve their adhesion properties.

This work deals with surface modification of CFs by an atmospheric pressure dielectric barrier discharge (DBD) in air. The treated and untreated carbon fibers were characterized photoelectron spectroscopy (XPS), scanning electron microscopy (SEM) and atomic force microscopy (AFM).

\section{Experimental}

The polyacrylonitrile fibers were purchased from Hexcel in the form of plain 3000 monofilaments in each tow with epoxy coating (sizing). Each CF monofilament has diameter of about $8 \mu \mathrm{m}$. The fibers were used as-received. The plasma reactor $(15.5-\mathrm{cm}$-diam cylindrica enclosure made of Plexiglas) operates in air with essentially uniform electric field, generating DBD between two circular aluminum electrodes with diameter of $9.5 \mathrm{~cm}$. The bottom reactor electrode was connected to a high-voltage source while the upper electrode was grounded. The power supply consists of a highvoltage transformer (Vrms 110/20000), powered by an auto transformer Varlac operating at frequency of $60 \mathrm{~Hz}$. A high voltage resistance $(1 \mathrm{k} \Omega)$ protects the transformer in the event of electric arc. Both reactor electrodes were covered by dielectric barriers. The dielectric used was Mylar ${ }^{\circledR}$ with a thickness of $0.5 \mathrm{~mm}$. The distance between the electrodes was set at $2.5 \mathrm{~mm}$ for all treatments. CF samples with area of $5.0 \times 5.0 \mathrm{~cm}^{2}$ were placed on the dielectric layer covering the bottom electrode. The DBD consists of large number of filamentary discharges randomly distributed over entire dielectric. Time for plasma treatment was set at 2, 5, 7.5 and 10 minutes while the voltage magnitude was kept the fixed at $35 \mathrm{kV}$ peak to peak.

\section{Results and discussions}

\subsection{Electric Measurements of DBD reacto}

The discharge current was obtained through measuring the potential drop across a serial resistor of $1200 \Omega$. The voltage applied on the reactor was measured by a 1000:1 high-voltage probe (Tektronix P6015A) and displayed on digital oscilloscope (Tektronix TDS 2024B). Figure 1 shows the typical waveforms of $\mathrm{DBD}$ voltage and current.

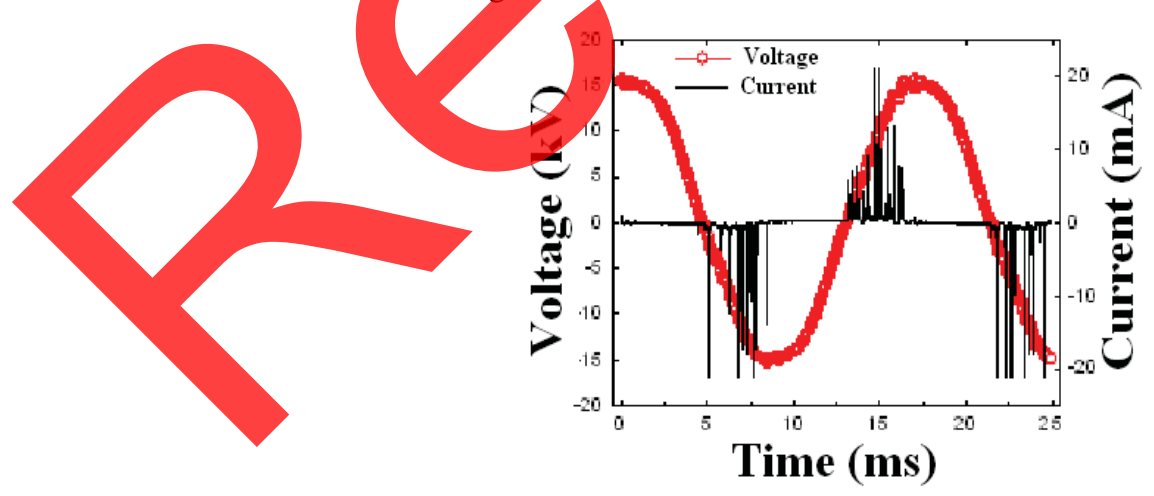

Figure 1: Typical waveforms of DBD voltage and current.

The charge transported in the discharges was calculated from the measurement of potential drop on a serial capacitor of $0.91 \mu \mathrm{F}$. 
The charge $Q(t)$ stored on the electrodes is represented as a function of $V(t)$ for one period to form so-called Lissajous figure (see figure 2). In case of filamentary DBD driven by a sinusoidal power source the typical shape of its $Q-V$ curve is a parallelogram. The area enclosed by the Lissajous figure gives the electrical energy consumed for voltage cycle. The discharge power of $6.6 \mathrm{~W}$ was then calculated by multiplying the electrical energy by the frequency of the applied voltage $(60 \mathrm{~Hz})$

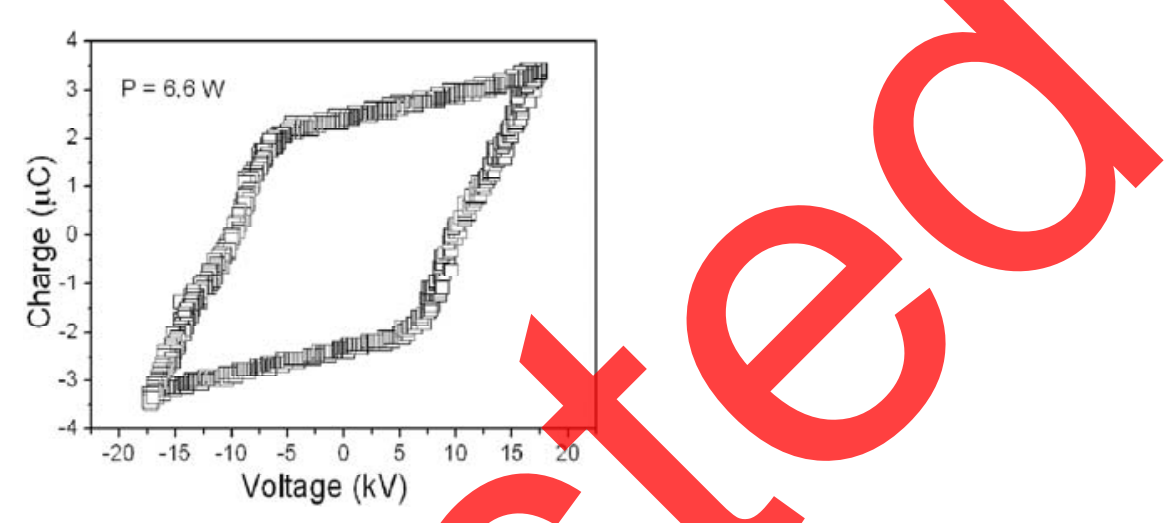

Figure 2: Lissajous figure $(\mathrm{Q} \times \mathrm{V})$ of $\mathrm{DBD}$

Discharge power as a function of the applied ac voltage is presented in figure 3. Beyond the onset voltage of $11 \mathrm{kV}$ the discharge power scales linearly with the voltage anplitude. This linear behavior is a typical feature of DBDs.

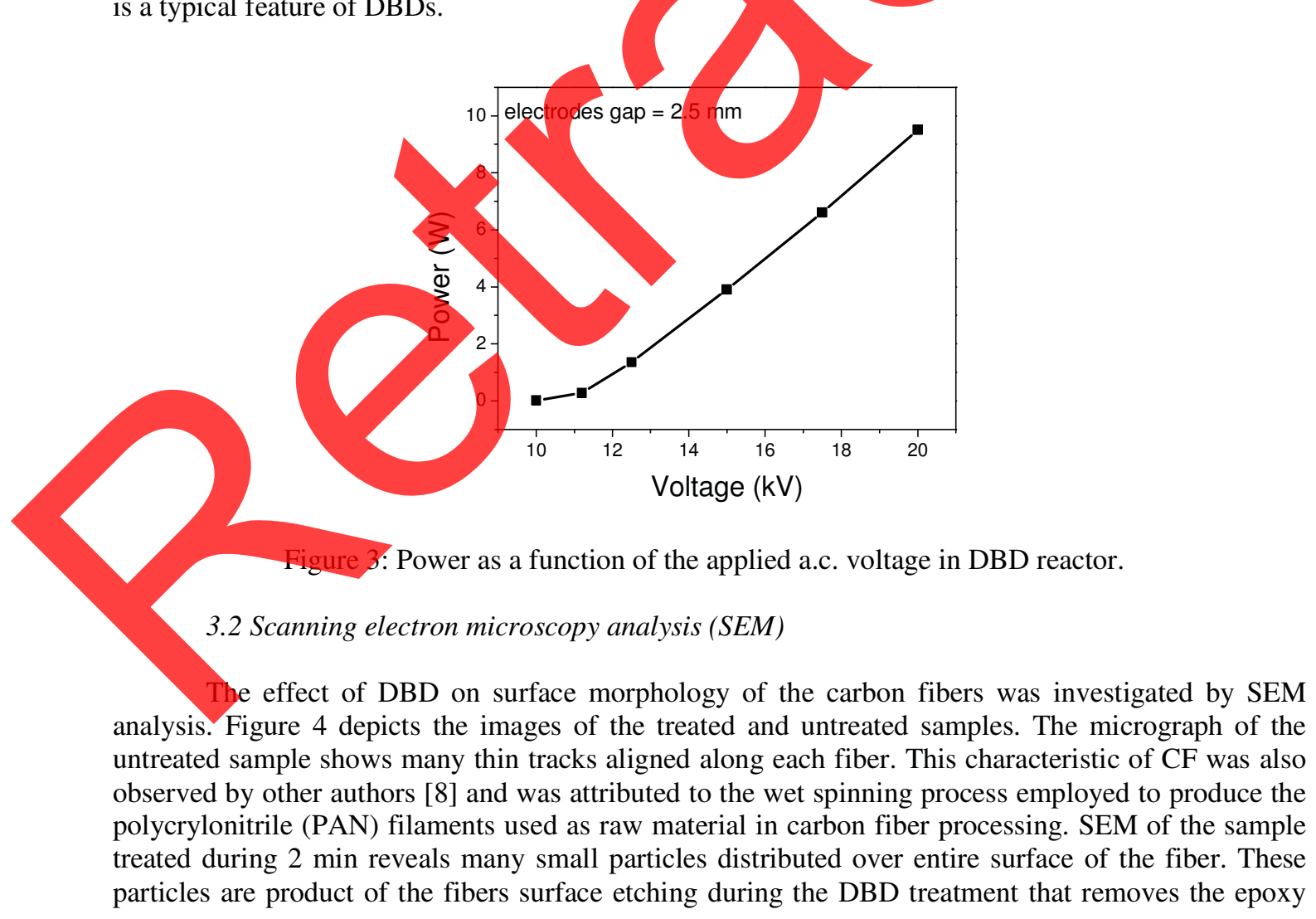


layer covering as-received samples. As the DBD-treatment time increases the quantity of epoxy covering removed by the DBD also increases.

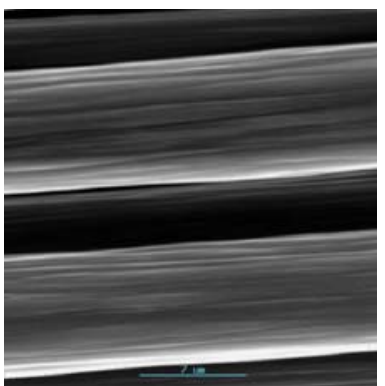

(a)

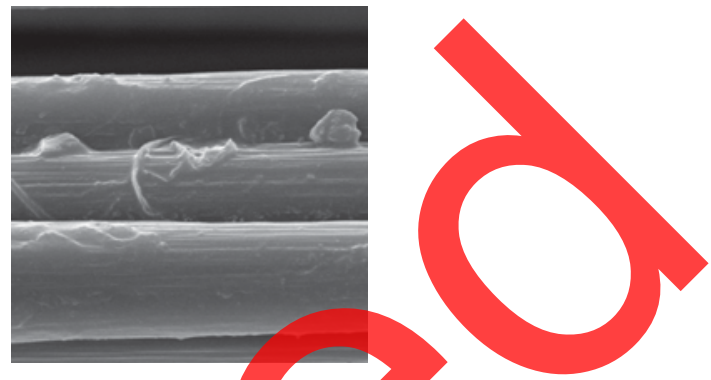

(b)

Figure 4: SEM images of carbon fibers: a) untreated sample; b) DBD treated sample

This kind of carbon fiber surface layer etching was also reported by other authors [1-10] after using RF plasma processing. The alteration of CF surface morphology was also confirmed by the AFM analysis.

\subsection{Atomic Force Microscope analysis (AFM)}

Results from AFM analysis indicate that the carbon fiber roughness increases as a result of the plasma treatment. Figure 5 and table 1 present the AFM images and the rms roughness values (Rq) of the untreated and treated specimens, respectively. The analyzed area was $64 \mu \mathrm{m}^{2}$.

The samples treated during 2 and 5 min showed up to two-fold increase of their roughness in comparison with the untreated fiber $(\mathrm{Rg}=14 \mathrm{~nm})$. This $\mathrm{CF}$ rotghness enhancement would result in a better adhesion between the polymer matrix and the carbon fibers by enlarging the surface area, which provides more points of contact/anchorage between the fiber and the matrix [9].

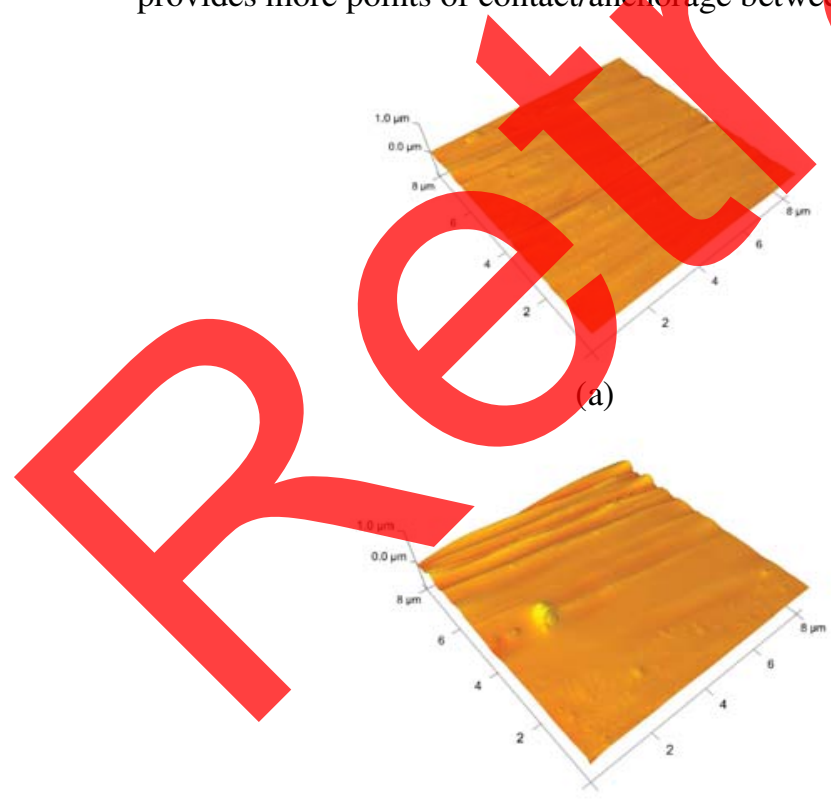

(c)

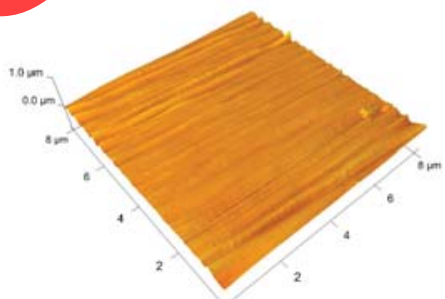

(b)

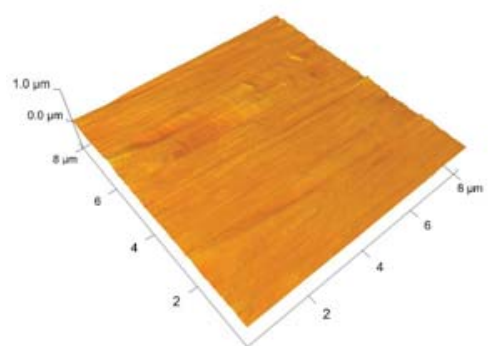

(d)

Figure 5: AFM images of the carbon fibers: a) untreated sample; DBD - treated samples b) $2 \mathrm{~min}$. c) $5 \mathrm{~min} \mathrm{d)} 10 \mathrm{~min}$ 
However the sample treated at 10 minutes shows roughness increase of only $20 \%$ in comparison with the standard specimen. This finding can be explained by the fact that during the first several minutes of treatment the soft epoxy layer covering the $\mathrm{CF}$ had been already removed and after that the etching goes on the naked $\mathrm{CF}$ with lower etching rate.

Table 1: Roughness values from AFM analysis.

\begin{tabular}{ll}
\hline Treatment time (min.) & Roughness $-\mathrm{Rq}(\mathrm{nm})$ \\
\hline As received & 14.0 \\
2 & 26.7 \\
5 & 29.5 \\
10 & 17.3 \\
\hline
\end{tabular}

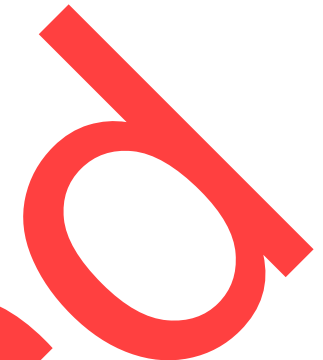

This result suggests that there exists an optimal processing time (on the order of $5 \mathrm{~min}$ ) which would favor good adhesion between two phases of composite material. Longer DBD reatment times cause decreasing of the CF surface roughness. Additionally, decrease the mechanical resistance of the $\mathrm{CF}$ fiber can be expected due to the excessive etching. Further mechanical tests will be imperative to prove this.

3.4 Photoelectron Spectroscopy (XPS)

Analysis of the CFs chemical composition, provided by the XPS analysis, showed that plasma treatment incorporate oxygen and nitrogen atoms onto the surface. The $\mathrm{O} / \mathrm{C}$ and N/C ratios of CFs are shown in table 2. The increase of the treatment time leads to more incorporation of $\mathrm{O}$ on the surface. The polar oxygen and nitrogen radicals formed on the surface will lead to increasing of the CF surface energy.

Table 2: Atomic percentage of the bond specimens from XPS analysis

\begin{tabular}{ccccccc}
\hline & $\mathbf{C 1}$ & $\mathrm{C} 2$ & $\mathrm{C} 3$ & $\mathbf{C 4}$ & & \\
& $\mathrm{C}-\mathrm{C}$ or $\mathrm{C}-\mathrm{H}$ & $\mathrm{C}-\mathrm{O}$ & $\mathrm{C}=\mathrm{O}$ & $\mathrm{O}-\mathrm{C}=\mathrm{O}$ & $\mathrm{O} / \mathrm{C}$ & $\mathrm{N} / \mathrm{C}$ \\
\hline As received & 62 & 28 & 10 & 0 & 0.24 & 0 \\
2 minutes & 43 & 41 & 10 & 6 & 0.49 & 0.075 \\
10 minutes & 35 & 44 & 11 & 10 & 0.6 & 0.081 \\
\hline
\end{tabular}

To trace the effect of plasma treatment on CF surface the $\mathrm{C} 1 \mathrm{~s}$ peak was investigated in details. Figure 6 depicts the deconvolution of $\mathrm{C}$ 1s peaks of untreated and plasma treated CFs. The as-received CF's peak was resolved into 3 contributions, whose binding energies are presented in figure 6 . As a result of the plasma exposure the $\mathrm{C} 1$ peak decreases while $\mathrm{C} 2$ peak increases and a new contribution $\mathrm{C} 4$ at $289.7 \mathrm{eV}$ due to $\mathrm{O}-\mathrm{C}=\mathrm{O}$ bonding appears. Table 2 presents the relative area of each contribution together with its assignme

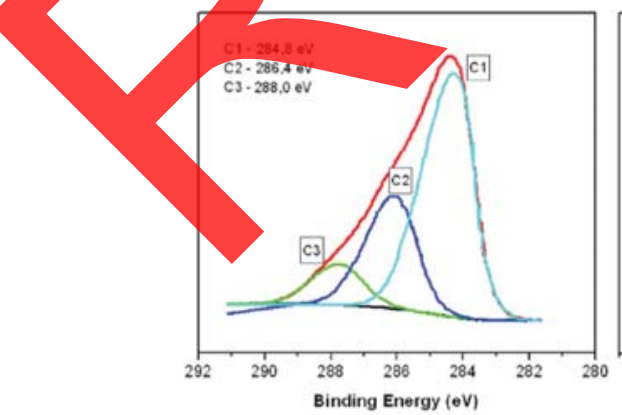

a)

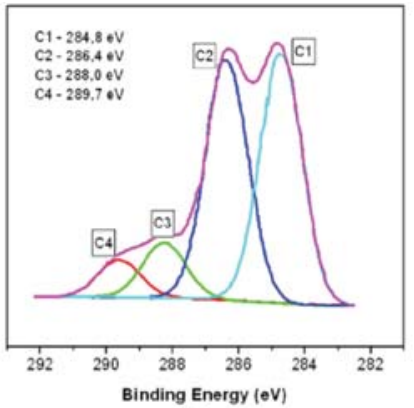

b)

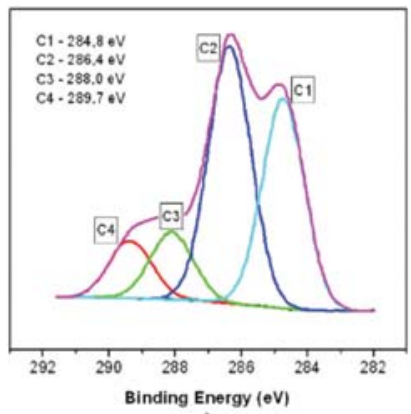

c)

Figure 6: XPS of carbon fibers: a) untreated sample; DBD - treated samples b) 2min. c) 10min. 
The $\mathrm{N}$ atoms detected on the surface of DBD-treated CF probably come from two sources: first the DBD discharge in air and in second place from the fiber itself. The polyacrylonitrile (PAN), which contains nitrogen, was used as fiber pre-cursor in the fiber manufacturing process. As long as the plasma treatment removes the epoxy layer and uncovers the CF naked surface the XPS analysis starts detecting $\mathrm{N}$ atoms from the fiber precursor.

From the XPS analysis one can conclude that oxygen atoms were efficiently incorporated on the surface of the treated fibers mainly in the form of $\mathrm{C}-\mathrm{O}$ and $\mathrm{O}-\mathrm{C}=\mathrm{O}$ bondings. It was also $\mathrm{obs}$ considerable increase of the $\mathrm{O} / \mathrm{C}$ ratio (up to $250 \%$ for $10 \mathrm{~min}$. DBD treatment). The polar oxygen radicals formed on the surface lead to increasing of the CF surface energy. Both, the modification of surface roughness and the surface oxidation contribute for enhancement of CF adhesion properties. These results are in agreement with the results of $\mathrm{J}$. Li [3] that presents a significant increase in oxygen and nitrogen concentration after the CF treatment with DBD at atmosphe

\section{Conclusion}

Carbon fibers were treated by DBD varying the treatment time while the applied voltage was fixed. SEM and AFM images showed surface morphological modifications of the carbon fibers after DBD process that resulted in two-fold increase of the roughness in comparison with the untreated sample $(14 \mathrm{~nm})$. XPS results determined that oxygen atoms were incorporated on the surface of the treated carbon fibers. Both the increase of surface roughness and the surface oxidation contribute for enhancement of CF adhesion properties.

\section{Acknowledgments}

This research has been supported by the FAPESP (processes: 2007/03714-3 and 2009/13843-0). Maria Lucia Brison is gratefully acknowledged for the SEM analy

\section{References}

[1] Sarraf H, Skarpova L and Louda P 2007 Surface modification of carbon fibers Journal Achievements in Materials and Manufacturing Engineering 25(2) 24

[2] Kusano Y, Andersen T L and Michelsen P K 2008 Atmospheric pressure plasma surface modification of carbon fibres Journal of Physics: Conference Series 100(2008)012002

[3] Li J 2009 The research on the interfacial compatibility of polypropylene composite filled with surface treated carbon fiber Applied Surface Science 2558682

[4] Jia C, Chen P, Li B,Wang Q, Lu C and Yu Q 2010 Effects of Twaron fiber surface treatment by air dielectric barrier discharge plasma on the interfacial adhesion in fiber reinforced composites Surface \& Coatings Technology 2043668

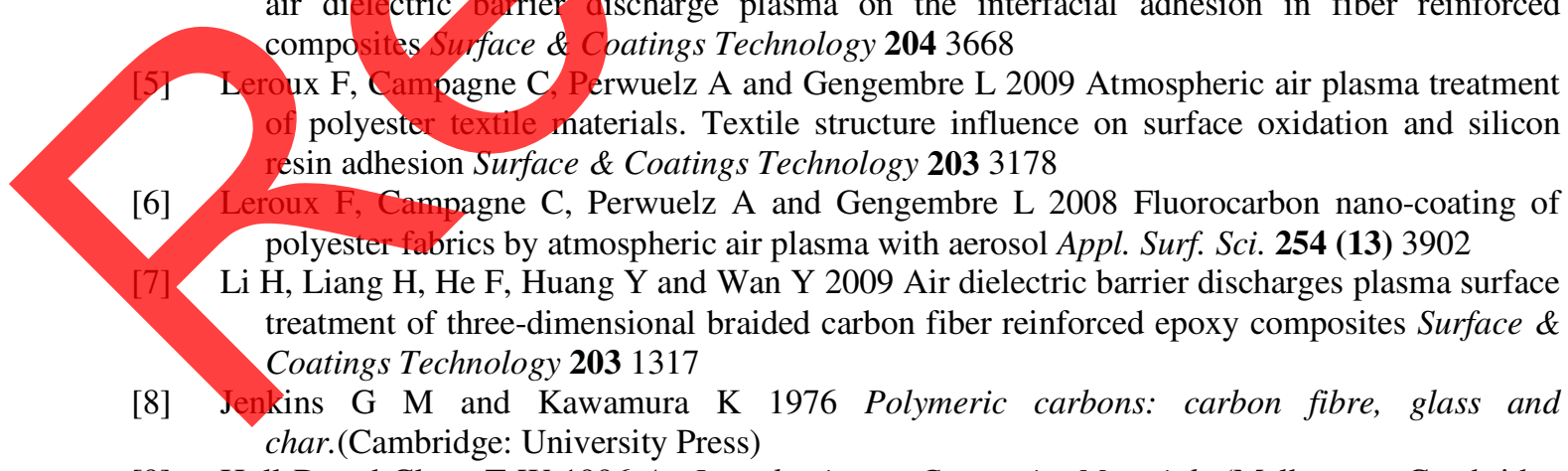

[9] Hull D and Clyne T W 1996 An Introduction to Composite Materials (Melbourne: Cambridge University Press)

[10] Nohara L B, Filho G P, Nohara E L, Kleinke, M U and Rezende, M C 2005 Evaluation of Carbon Fiber SurfaceTreated by Chemical andCold Plasma Processes Materials Research 8(3) 281 